\title{
Ablation of atrial fibrillation during coronary artery bypass grafting: Late outcomes in a Medicare population
}

S. Chris Malaisrie, MD, ${ }^{a}$ Patrick M. McCarthy, MD, ${ }^{a}$ Jane Kruse, BSN, ${ }^{a}$ Roland A. Matsouaka, PhD, ${ }^{\text {b,c }}$ Andrei Churyla, MD, ${ }^{\mathrm{a}}$ Maria V. Grau-Sepulveda, MD, ${ }^{\mathrm{b}}$ Daniel J. Friedman, MD, ${ }^{\mathrm{b}}$ and J. Matthew Brennan, MD

\section{ABSTRACT}

Background: This study compares outcomes of patients with preoperative atrial fibrillation undergoing coronary artery bypass grafting (CABG) with or without concomitant atrial fibrillation ablation in a nationally representative Medicare cohort.

Objectives: This study examined early and late outcomes in CABG patients with a preoperative history of atrial fibrillation to determine the correlation between surgical atrial fibrillation ablation to mortality and stroke or systemic embolization.

Methods: In the Medicare-linked Society of Thoracic Surgeons database, 361,138 patients underwent isolated CABG from 2006 to $2013 ; 34,600$ (9.6\%) had preoperative atrial fibrillation; $10,541(30.5 \%)$ were treated with surgical ablation (ablation group), and 23,059 were not (no ablation group). Propensity score matching was performed using a hierarchical mixed model. Long-term survival was summarized using Kaplan-Meier curves and Cox regression models with robust variance estimation. The stroke or systemic embolization incidence was modeled using the FineGray model. Median follow-up was 4 years.

Results: Long-term mortality in propensity score-matched CABG patients (mean age 74 years; Society of Thoracic Surgeons risk score, 2.25) receiving ablation versus no ablation was similar (log-rank $P=.30$ ). Stroke or systemic embolization occurred in $2.2 \%$ versus $2.1 \%$ at 30 days and $9.9 \%$ versus $12.0 \%$ at 5 years (Gray $P=.0091$ ). Landmark analysis from 2 to 5 years showed lower mortality (hazard ratio, 0.89; 95\% confidence interval 0.82-0.97; $P=.0358$ ) and lower risk of stroke or systemic embolization (hazard ratio, $0.73 ; 95 \%$ confidence interval, $0.61-0.87 ; P=.0006)$ in the ablation group.

Conclusions: Concomitant ablation in CABG patients with preoperative atrial fibrillation is associated with lower stroke or systemic embolization and mortality in patients who survive more than 2 years. ( $J$ Thorac Cardiovasc Surg 2021;161:1251-61)

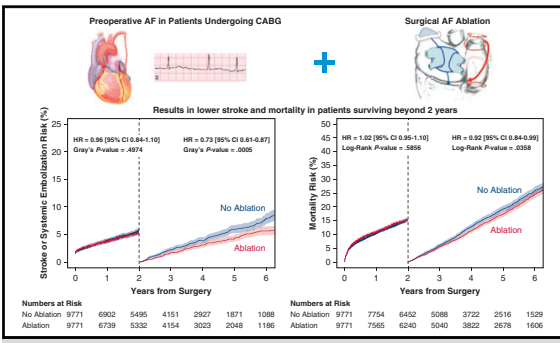

Surgical ablation of AF in CABG patients is associated with lower mortality at 5 years.

\section{CENTRAL MESSAGE}

Concomitant AF treatment during coronary artery bypass surgery is associated with fewer stroke and systolic embolic events as well as higher survival in patients who survive 2 years beyond surgery.

\section{PERSPECTIVE}

Treating AF during cardiac surgery is a class I indication in patients with a suitable perioperative risk. Ablation in CABG patients with preoperative $\mathrm{AF}$ is associated with lower stroke and systemic embolization and mortality in patients who survive 2 years. AF ablation was associated with a higher operative mortality in patients with a $\mathrm{CHA}_{2} \mathrm{DS}_{2}-\mathrm{VASC}$ score of 7 to 9

See Commentaries on pages 1262 and 1263.
The incidence of preoperative atrial fibrillation (AF) in patients undergoing coronary artery bypass grafting (CABG) ranges from $5 \%$ to $10 \% .{ }^{1,2}$ Preoperative $\mathrm{AF}$ is an

\footnotetext{
From the a Division of Cardiac Surgery, Bluhm Cardiovascular Institute, Northwestern University, Northwestern Memorial Hospital, Chicago, Ill; ${ }^{\mathrm{b}}$ Duke Clinical Research Institute, School of Medicine, and ${ }^{\mathrm{c}}$ Department of Biostatistics and Bioinformatics, Duke University, Durham, NC.

Supported by institutional funding from Northwestern University, Chicago Ill.

Read at the 98th Annual Meeting of The American Association for Thoracic Surgery, San Diego, California, April 28-May 1, 2018.

Received for publication April 23, 2019; revisions received Oct 15, 2019; accepted for publication Oct 23, 2019; available ahead of print Nov 29, 2019.
}

independent risk factor for worse perioperative outcomes and decreased long-term survival in patients who undergo CABG when compared with patients without preoperative

\footnotetext{
Address for reprints: S. Chris Malaisrie, MD, Division of Cardiac Surgery, Bluhm Cardiovascular Institute, Northwestern University Feinberg School of Medicine 201 E Huron St, Suite 11-140, Chicago, IL 60611-2908 (E-mail: Chris. Malaisrie@nm.org). $0022-5223 / \$ 36.00$

Copyright (C) 2019 by The American Association for Thoracic Surgery https://doi.org/10.1016/j.jtcvs.2019.10.159
} 


\section{Abbreviations and Acronyms \\ $\mathrm{AF} \quad=$ atrial fibrillation \\ $\mathrm{CABG}=$ coronary artery bypass grafting \\ $\mathrm{CHA}_{2} \mathrm{DS}_{2}$-VASc $=$ congestive heart failure, hypertension, age $\geq 75$ years, \\ diabetes, stroke, vascular \\ disease, age 65 to 74 years, sex category \\ CIF = cumulative incidence function \\ CMS $\quad=$ Centers for Medicare and Medicaid Services \\ K-M = Kaplan-Meier \\ LAA $\quad=$ left atrial appendage \\ PS $\quad=$ propensity score \\ STS $\quad=$ Society of Thoracic Surgeons}

File for postdischarge deaths. ${ }^{12}$ The secondary outcomes were stroke or systemic embolization (ie, stroke, hemorrhagic stroke, transient ischemic attack, or systemic arterial embolism $)^{13}$ and in-hospital major morbidity.

Incident stroke or systemic embolization was defined by using STS registry data to account for in-hospital strokes and Medicare Part A data to identify subsequent re-hospitalizations with stroke or systemic embolization as a primary diagnosis (International Classification of Diseases, ninth revision codes: 433.1, 434.x1, 430, 431, 432.0, 432.1, 432.9, 444,x, and 435.x).

In-hospital major morbidity, a previously defined composite, ${ }^{14,15}$ referred to any of the following postprocedure complications: permanent stroke, new cases of renal failure, prolonged ventilation (ie, ventilation longer than 24 hours after surgery), reoperation for cardiac reasons (ie, graft dysfunction, bleeding, valve dysfunction, or other), and deep sternal wound infection.

\section{Statistical Analysis}

Patients treated in a given hospital share some commonalities inherent to that hospital (compared with patients treated elsewhere) that may influence how they were treated and thus influence their outcomes above and beyond the effects of treatment itself. Therefore, propensity scores (PS) for surgical ablation were determined using a hierarchical mixed model that includes both patient and hospital characteristics as well as a random intercept (with hospitals as random effects) to holistically capture and control for any confounding due to inherent hospital-related commonalities. Patient variables were based in the validated American College of Cardiology Foundation and the Society of Thoracic Surgeons Collaboration on the Comparative Effectiveness of Revascularization Strategies model ${ }^{16}$ for predictors of long-term mortality after CABG (Table 1). We also included region (ie, Northeast, West, South, or Midwest), hospital teaching status, hospital average annual volume of CABG in patients aged 65 and older and preoperative medications: aspirin, beta-blockers, angiotensin-converting enzyme inhibitors, statins, and anticoagulants. Consistent with the validated STS risk models, ${ }^{16}$ missing values $(<3 \%)$ were imputed with relevant groups-specific medians for continuous variables and most common category for categorical ones.

A 1-to-1 optimal matching algorithm was used to obtain a matched sample to overcome differences in potential confounders between the 2 study groups. To assess balance, we compared the distribution of baseline characteristics before and after matching. Absolute values of standardized mean differences $<10 \%$ suggest adequate balance. ${ }^{17}$ Before matching, the standardized differences ranged between -23 and 14 , whereas in the matched sample, they ranged between -1.7 and 2.4 , which indicates that balance was achieved after matching (Figure 2). Because use versus nonuse of ablation could be influenced by unmeasured confounders that cannot be adjusted for using registry variables, we tested the association between ablation and the falsification end point of fracture. In addition, to account for possible residual confounding, we use multivariate Cox-regression analysis in the matched sample (same covariates as in the American College of Cardiology Foundation and the Society of Thoracic Surgeons Collaboration on the Comparative Effectiveness of Revascularization Strategies model ${ }^{16}$ ) for long-term outcomes. Results were virtually the same as univariate Cox model (Table E1). A null association between the exposure (ablation) and a falsification suggested balance among unmeasured confounders.

The study groups were summarized before and after matching using medians and interquartile ranges (25th and 75th percentiles) for continuous variables and frequency counts and percentages for categorical variables and in-hospital outcomes. Differences in distributions between groups were evaluated with Wilcoxon and Pearson $\chi^{2}$ tests, respectively.

For in-hospital outcomes, we computed odds ratios and $95 \%$ confidence intervals (CIs) for the overall and matched sample using generalized estimated equations logistic regression to account for hospital clustering of patients.

Time-to-event analysis was used to compare long-term survival and stroke or systemic embolization occurrence by group. For survival, patient follow-up was censored at the end of study period (January 1, 2014).

\section{End Points}

The primary outcome was all-cause mortality after CABG using STS registry data for in-hospital deaths and the linked Medicare Denominator 


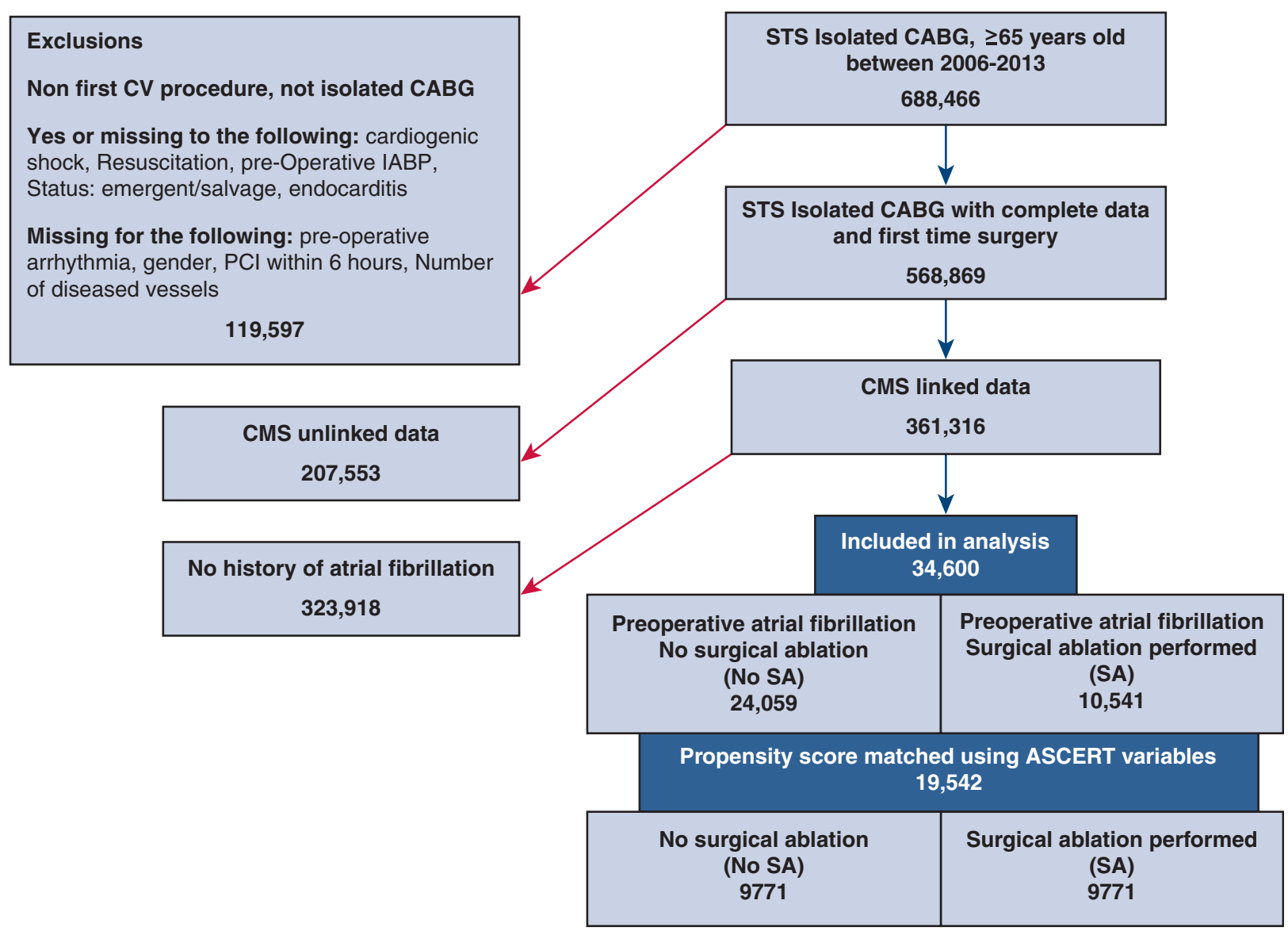

FIGURE 1. Flow diagram of the study cohort. The Society of Thoracic Surgeons (STS) database was queried for patients undergoing isolated coronary artery bypass graft $(C A B G)$ between 2006 and 2013. Exclusions and numbers of patients removed are shown on the left. This resulted in 34,600 patients with preoperative atrial fibrillation $(\mathrm{AF})$ who were divided into those with or without surgical ablation during the $\mathrm{CABG}$ procedure. $C V$, Cardiovascular; $C M S$, Centers for Medicare and Medicaid Services; $P C I$, percutaneous coronary intervention.

Product-limit Kaplan-Meier (K-M) survival and failure estimates were computed for each group in the unmatched and matched samples and compared via log-rank tests. Cox proportional hazard regression models were used to compute hazard ratios for ablation versus no ablation in both samples. Because patients from a given hospital share commonalities compared to patients from different hospitals, we used a robust sandwich variance estimation to account for hospital clustering of patients and computed $95 \%$ CIs accordingly. The proportional hazard assumption was tested using $\log$-log survival plots $(\log [-\log ]$ survival vs $\log$-time) and interactions between study groups and log-time. Although the assumption was met in the overall sample, both methods suggested a marginal violation of the assumption in the matched sample, with curves crossing 2 years after surgery and a statistically significant interaction with time $(P=.01)$. Given these results, hazard ratios (HRs) were computed in the unmatched and matched samples for the overall follow-up period, but we also performed a landmark analysis at 2 years to explore earlier versus later effects of surgical ablation in survival. Both, K-M survival curves and HRs were computed for each period.

For stroke or systemic embolization and the falsification end point of fracture, death was considered a competing risk. Follow-up was censored at death date, end of fee-for-service date, or end of study period, whichever came first. Date for in-hospital strokes postprocedure was not available and surgery date was assigned as the event date ( $23 \%$ of all strokes). For regression analysis, the Fine and Gray method was used to calculate the subdistribution HRs. The proportional hazards assumption (accounting for competing risk of death) was tested by plotting Schoenfeld residuals ${ }^{18,19}$ for each treatment group versus log-time and also with interaction terms between study groups and log-time in regression models. Results suggested a violation of the assumption in the matched sample ( $P$ value for interaction with log-time in the matched sample was .0064 for stroke or systemic embolization). Therefore, a landmark analysis at 2 years was performed and cumulative incidence function curves and subdistribution HRs were computed for each period.

All tests were 2-sided. Analyses were performed using SAS (version 9.4, SAS Institute Inc, Cary, NC).

\section{RESULTS}

\section{Patient and Operative Characteristics}

Compared with patients treated with ablation, patients in the no ablation group were older, had a higher incidence of renal failure (glomerular filtration rate $<30$ or undergoing dialysis), diabetes, chronic lung disease, lower ejection fraction, and New York Heart Association functional class IV, incidence of dyslipidemia, and hypertension was similar. After PS matching, the groups were statistically similar except for fewer myocardial infarctions in the ablation group $(40.4 \%)$ compared with the no ablation group 
TABLE 1. Baseline and operative characteristics of patients with preoperative atrial fibrillation in the no surgical ablation and surgical ablation groups

\begin{tabular}{|c|c|c|c|c|c|c|}
\hline \multirow[b]{2}{*}{ Variable } & \multicolumn{3}{|c|}{ Unmatched } & \multicolumn{3}{|c|}{ Propensity score matched } \\
\hline & $\begin{array}{l}\text { No ablation } \\
(\mathrm{n}=\mathbf{2 4 , 0 5 9 )}\end{array}$ & $\begin{array}{c}\text { Ablation } \\
(\mathrm{n}=\mathbf{1 0}, \mathbf{5 4 1})\end{array}$ & $P$ value & $\begin{array}{c}\text { No ablation } \\
(\mathrm{n}=9771)\end{array}$ & $\begin{array}{c}\text { Ablation } \\
(\mathbf{n}=9771)\end{array}$ & $P$ value \\
\hline Age (y) & $75(71,80)$ & $74(70,78)$ & $<.0001$ & $74(69,79)$ & $74(70,78)$ & .1049 \\
\hline Female & $6920(29)$ & $2561(24)$ & $<.0001$ & $2370(24)$ & $2439(25)$ & .2729 \\
\hline Body mass index & $28.10(25,32)$ & $28.61(25,33)$ & .954 & $28(25,32)$ & $28(25,32)$ & .9893 \\
\hline Height $(\mathrm{cm})$ & $173(165,180)$ & $175(168,180)$ & $<.0001$ & $175(168,180)$ & $175(168,180)$ & .6838 \\
\hline \multicolumn{7}{|l|}{ Race } \\
\hline Other & $428(1.8)$ & $208(2.0)$ & $<.0001$ & $174(1.8)$ & $176(1.8)$ & .9835 \\
\hline Asian & $283(1.2)$ & $102(1.0)$ & & $102(1.0)$ & $99(1.0)$ & \\
\hline Hispanic & $548(2.3)$ & 138 (1.3) & & $130(1.3)$ & 138 (1.4) & \\
\hline Black & $751(3.1)$ & $217(2.1)$ & & $204(2.1)$ & $210(2.2)$ & \\
\hline White & $21,952(91.2)$ & $9848(93.4)$ & & $9132(93.5)$ & $9122(93.4)$ & \\
\hline Missing & $97(0.4)$ & $28(0.3)$ & & $29(0.3)$ & $26(0.3)$ & \\
\hline Current smoking & $3111(12.9)$ & $1160(11.0)$ & $<.0001$ & $1126(11.5)$ & $1108(11.3)$ & .6857 \\
\hline Diabetes & 9903 (41.2) & 4164 (39.5) & $<.0001$ & $3832(39.2)$ & $3844(39.3)$ & .8209 \\
\hline Hypertension & $21,615(89.8)$ & $9417(89.3)$ & .1523 & $8695(89.0)$ & $8728(89.3)$ & .4477 \\
\hline Dyslipidemia & $19,776(82.4)$ & 8687 (82.2) & $<.0001$ & $8102(83.0)$ & $8063(82.5)$ & .4132 \\
\hline Peripheral vascular disease & $5355(22.3)$ & $1837(17.4)$ & $<.0001$ & $1758(18.0)$ & $1760(18.0)$ & .9783 \\
\hline Renal failure* & $1625(6.8)$ & $423(4.0)$ & $<.0001$ & $434(4.4)$ & $452(4.6)$ & .5319 \\
\hline Glomerular filtration rate & $61(49,74)$ & $65(53,75)$ & $<.0001$ & $64.7(52,80)$ & $64.7(52,75)$ & .2077 \\
\hline Chronic lung disease & & & $<.0001$ & & & .2990 \\
\hline Severe & $1644(6.8)$ & $552(5.2)$ & & $533(5.5)$ & $532(504)$ & \\
\hline Moderate & $2179(9.1)$ & $788(7.5)$ & & 707 (7.2) & $733(7.5)$ & \\
\hline Cerebrovascular disease & $5735(23.8)$ & 2204 (20.9) & $<.0001$ & $2098(21.5)$ & $2077(21.3)$ & .5540 \\
\hline Transient ischemic attack & $1620(6.7)$ & $653(6.2)$ & .0627 & $651(6.7)$ & $608(6.2)$ & .2103 \\
\hline Previous carotid surgery & $1739(7.2)$ & $583(5.5)$ & $<.0001$ & $554(5.7)$ & $557(5.7)$ & .9262 \\
\hline Carotid stenosis $>75 \%$ & $964(4.0)$ & $319(3.0)$ & $<.0001$ & $315(3.2)$ & $305(3.1)$ & .6832 \\
\hline Immunosuppressive treatment & $993(4.1)$ & $342(3.2)$ & $<.0001$ & $306(3.1)$ & $318(3.3)$ & .6272 \\
\hline $\begin{array}{l}\text { Preoperative myocardial } \\
\text { infarction }\end{array}$ & & & $<.0001$ & & & .0015 \\
\hline$\leq 6 \mathrm{~h}$ & $47(0.2)$ & $12(0.1)$ & & $8(0.1)$ & $12(0.1)$ & \\
\hline$>6 \mathrm{~h}$ but $<24 \mathrm{~h}$ & $212(0.9)$ & $43(0.4)$ & & $43(0.4)$ & $42(0.4)$ & \\
\hline Between 1 and $21 \mathrm{~d}$ & $7476(31.1)$ & $2211(21.0)$ & & $2031(20.8)$ & $2130(21.8)$ & \\
\hline No myocardial infarction & $11,850(49.3)$ & $6350(60.2)$ & & $5696(58.3)$ & $5822(59.6)$ & \\
\hline \multicolumn{7}{|l|}{ Coronary artery disease } \\
\hline Left main $\geq 50 \%$ & $8713(36.2)$ & $3360(31.9)$ & $<.0001$ & $3174(32.5)$ & $3173(32.5)$ & .9838 \\
\hline 3 vessels & $18,524(77.0)$ & $7946(75.4)$ & .0043 & $7443(76.2)$ & $7416(75.9)$ & .8993 \\
\hline 2 vessels & $4720(19.6)$ & $2225(21.1)$ & & $1993(20.4)$ & $2014(20.61)$ & \\
\hline 1 vessel & $815(3.4)$ & $370(3.5)$ & & $335(3.4)$ & $341(3.5)$ & \\
\hline $\begin{array}{l}\text { Left ventricular ejection fraction } \\
\quad \geq 55 \%\end{array}$ & $10,761(46)$ & $4971(48.2)$ & $<.0001$ & $4631(48.8)$ & $4570(47.81)$ & .4303 \\
\hline NYHA functional class IV & $1796(25)$ & $608(22.5)$ & .0001 & $578(23.1)$ & $573(22.5)$ & .6947 \\
\hline $\begin{array}{l}\text { Aortic stenosis, moderate or } \\
\text { severe }\end{array}$ & $1124(4.7)$ & $383(3.6)$ & $<.0001$ & 347 (3.6) & $362(3.7)$ & .5651 \\
\hline Urgent procedure & $14,303(59.5)$ & $5366(50.9)$ & $<.0001$ & $5040(51.6)$ & 5047 (51.7) & .9202 \\
\hline
\end{tabular}




\begin{tabular}{|c|c|c|c|c|c|c|}
\hline \multirow[b]{2}{*}{ Variable } & \multicolumn{3}{|c|}{ Unmatched } & \multicolumn{3}{|c|}{ Propensity score matched } \\
\hline & $\begin{array}{l}\text { No ablation } \\
(n=24,059)\end{array}$ & $\begin{array}{c}\text { Ablation } \\
(\mathrm{n}=\mathbf{1 0}, \mathbf{5 4 1})\end{array}$ & $P$ value & $\begin{array}{c}\text { No ablation } \\
(\mathrm{n}=9771)\end{array}$ & $\begin{array}{c}\text { Ablation } \\
(\mathrm{n}=9771)\end{array}$ & $P$ value \\
\hline $\mathrm{CHA}_{2} \mathrm{DS}_{2}$-VASc score & & & $<.0001$ & & & 0.138 \\
\hline $1-3$ & $9560(65.5)$ & $5028(34.5)$ & & $4608(50.1)$ & $4574(49.8)$ & \\
\hline $4-6$ & $13,145(72.1)$ & $5088(27.9)$ & & $4805(50.1)$ & 4785 (49.9) & \\
\hline $7-9$ & $1354(76.1)$ & 425 (23.9) & & $358(46.5)$ & $412(53.5)$ & \\
\hline STS mortality risk score $\dagger$ & $2.84(1.6,4.6)$ & $2.19(1.4,3.6)$ & $<.0001$ & $2.25(1.4,3.7)$ & $2.3(1.4,3.7)$ & .9239 \\
\hline Predicted major morbidity & $19.34(13.8,28)$ & $16.58(12.1,23.4)$ & $<.0001$ & $16.77(12.2,23.9)$ & $16.8(12.3,23.8)$ & .9303 \\
\hline Predicted stroke & $1.72(1.2,2.6)$ & $1.44(1.02,2.13)$ & $<.0001$ & $1.46(1,2.2)$ & $1.47(1,2.2)$ & .7821 \\
\hline Predicted renal failure & $4.69(2.7,9)$ & $3.92(2.33,7.25)$ & $<.0001$ & $3.92(2.3,7.5)$ & $3.97(2.4,7.4)$ & .3675 \\
\hline Predicted prolonged ventilation & $11.87(8.1,18.3)$ & $9.89(6.9,14.7)$ & $<.0001$ & $10.05(7.1,15.1)$ & $10(7,15)$ & .9011 \\
\hline $\begin{array}{l}\text { Predicted deep sternal wound } \\
\text { infection }\end{array}$ & $0.39(0.25,0.64)$ & $0.35(0.24,0.56)$ & $<.0001$ & $0.35(0.24,0.57)$ & $0.35(0.24, .056)$ & .5853 \\
\hline Predicted reoperation & $6.98(5.5,9.3)$ & $6.22(5,8.1)$ & $<.0001$ & $6.28(5.1,8.2)$ & $6.28(5.06,8.13)$ & .8795 \\
\hline $\begin{array}{l}\text { Cardiopulmonary bypass time } \\
\text { (min) }\end{array}$ & $90(70,115)$ & $107(84,136)$ & $<.0001$ & $90(70,115)$ & $108(85,137)$ & $<.0001$ \\
\hline
\end{tabular}

Values for continuous variables are presented as median (first quartile, third quartile); for variables with discrete distributions, values are $\mathrm{n}$ (\%). NYHA, New York Heart Association, $\mathrm{CHA}_{2} \mathrm{DS}_{2}-\mathrm{VASC}$, congestive heart failure, hypertension, age $\geq 75$ years, diabetes, previous stroke/transient ischemic attack-vascular disease, age $65-74$ years, sex category; STS, Society of Thoracic Surgeons. *Glomerular filtration rate $<30$ or receiving dialysis. $\dagger$ STS risk scores use the 2007 model.

$(41.7 \%)$ (Table 1$)$. Mean cardiopulmonary bypass time was longer in the ablation group (113 \pm 43 minutes vs $95 \pm 36$ minutes; $P<.0001)$ for the unmatched and matched groups. There were no data available on the ablation lesion sets or management of the left atrial appendage (LAA).

\section{Perioperative Results}

In the unmatched analysis, in-hospital outcomes were not statistically different. In the matched analysis, patients in the ablation group had greater in-hospital mortality, prolonged ventilation, and new renal failure compared with the no ablation group. Subanalysis of the operative mortality showed that patients with higher Congestive heart failure, hypertension, age $\geq 75$ years, diabetes, stroke, vascular disease, age 65-74 years, sex category $\left(\mathrm{CHA}_{2} \mathrm{DS}_{2}\right.$-VASc) scores revealed higher operative mortality in patients with a $\mathrm{CHA}_{2} \mathrm{DS}_{2}$-VASc score of 7 to 9 , and the lowest operative mortality in the ablation group with a $\mathrm{CHA}_{2} \mathrm{DS}_{2}$-VASc score of 1 to 3 (Table 2).

\section{Long-term Results: Mortality and Stroke or Systemic Embolization}

In the unmatched analysis, the 1-year overall K-M failure estimates (mortality incidence) was $10.8 \%(95 \% \mathrm{CI}$, $10.2 \%-11.4 \%$ ) in the ablation group compared with $13.3 \%(95 \%$ CI, $12.9 \%-13.8 \%)$ in the no ablation group. The 5-year overall mortality was $29.9 \% \quad(95 \%$ CI, $28.8 \%-31.0 \%$ ) in the ablation group compared with $37.1 \%(95 \% \mathrm{CI}, 36.3 \%-37.8 \%)$ in the no ablation group. The HR for mortality (Figure 3, A) was 0.78 (95\% CI, 0.74-0.82). The 1-year CIF for stroke or systemic embolization was $3.7 \%(95 \%$ CI, 3.4\%-4.2\%) in the ablation group compared with $4.4 \%(95 \%$ CI, $4.1 \%-4.7 \%)$ in the no ablation group. The 5-year overall stroke or systemic embolization (Figure 4, $A$ ) was 8.8\% (95\% CI, 8.2\%-9.5\%) in the ablation group compared with $10.7 \%$ (95\% CI, $10.2 \%$ $11.2 \%)$ in the no ablation group. The HR was $0.84(95 \%$ CI, 0.77-0.91).

After PS matching, the 1-year overall mortality incidence was $11.1 \%(95 \% \mathrm{CI}, 10.5 \%-11.7 \%)$ in the ablation group compared with $10.6 \%(95 \% \mathrm{CI}, 10.0 \%-11.3 \%)$ in the no ablation group. The 5-year overall mortality was $30.2 \%$ (95\% CI, 29.1\%-31.4\%) in the ablation group compared with $31.7 \%(95 \% \mathrm{CI}, 30.6 \%-32.9 \%)$ in the no ablation group (log-rank $P=.303$ ) (Figure $3, B$ ). The 1 -year CIF for stroke or systemic embolization was 3.8\% (95\% CI, $3.4 \%-4.2 \%$ ) in the ablation group compared with $3.9 \%$ $(95 \%$ CI, 3.5\%-4.3\%) in the no ablation group. The 5year overall stroke or systemic embolization was $8.8 \%$ $(95 \%$ CI, 8.1\%-9.5\%) in the ablation group compared with $10.5 \%(95 \% \mathrm{CI}, 9.7 \%-11.2 \%)$ in the no ablation group (log-rank $P=.009$ ) (Figure $4, B$ ).

\section{Landmark Analysis at 2 Years: Mortality and Stroke or Systemic Embolization}

After PS matching, the difference in 2-year mortality was not statistically significant between ablation and no ablation groups (HR, 1.00; 95\% CI, 0.93-1.08; log-rank $P=.59$ ). Among patients surviving past 2 years, mortality was lower in the ablation group (HR, 0.89; 95\% CI, 0.82-0.97; logrank $P=.04$ ) (Figure $3, C$ and $D$ ).

Similarly, the difference in 2-year incidence of stroke or systemic embolization was not statistically significant between ablation and no ablation groups (HR, 0.96; 95\% 


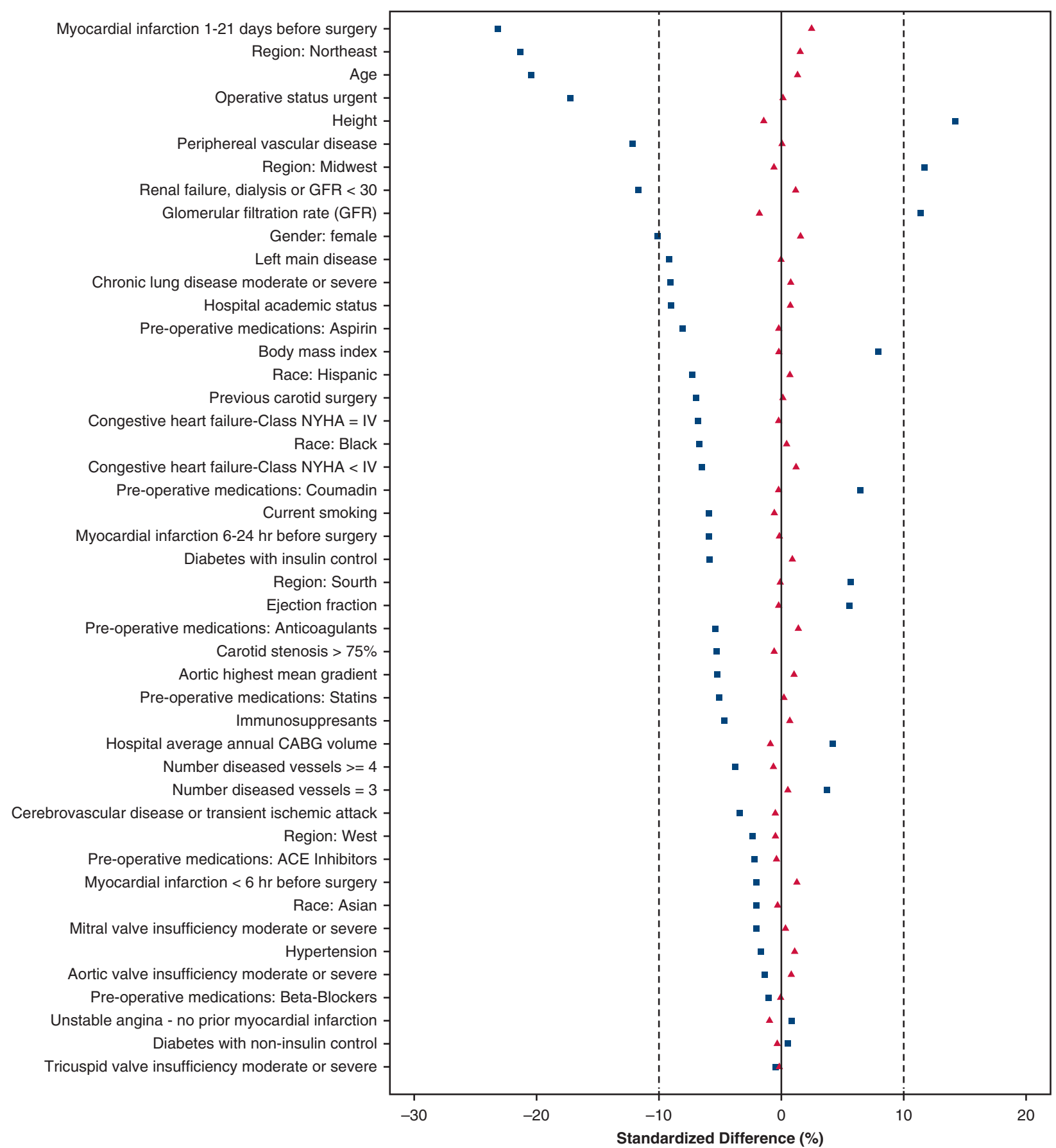

FIGURE 2. Propensity score-match assessment of balance before and after matching. A 1-to-1 optimal matching algorithm was used to overcome differences in potential confounders between the 2 study groups. We compared the distribution of baseline characteristics before (blue squares) and after matching (triangles). Before matching, the standardized differences ranged between -23 and 14, whereas in the matched sample, they ranged between -1.7 and 2.4 , which indicates balance was achieved. NYHA, New York Heart Association, $C A B G$, coronary artery bypass graft.

CI, 0.84- 1.10; Gray test $P=.50)$. Among patients surviving past 2 years, incidence of stroke or systemic embolization was lower in the ablation group (HR, 0.73 ; 95\% CI, 0.61-0.87; Gray test $P=.0005$ ) (Figure 4, $C$ and $D$ ).

\section{DISCUSSION}

This is the largest contemporary study of ablation in CABG patients compared with those who had untreated AF. In this study ablation was associated with a small but statistically significant higher operative mortality. In 
TABLE 2. In-hospital outcomes by surgical ablation group in unmatched and propensity score-matched patients

\begin{tabular}{|c|c|c|c|c|c|c|c|c|}
\hline \multirow[b]{2}{*}{ Variable } & \multicolumn{3}{|c|}{ Unmatched } & \multicolumn{5}{|c|}{ Propensity score matched } \\
\hline & $\begin{array}{c}\text { No ablation } \\
\text { group } \\
(\mathrm{n}=\mathbf{2 4 , 0 5 9 )}\end{array}$ & $\begin{array}{c}\text { Ablation } \\
\text { group } \\
(\mathbf{n}=\mathbf{1 0 , 5 4 1 )}\end{array}$ & $P$ value & $\begin{array}{c}\text { No ablation } \\
\text { group } \\
(\mathbf{n}=9771)\end{array}$ & $\begin{array}{c}\text { Ablation } \\
\text { group } \\
(\mathbf{n}=\mathbf{9 7 7 1})\end{array}$ & $P$ value & $\begin{array}{c}\text { Odds ratio } \\
(95 \% \text { confidence } \\
\text { interval })\end{array}$ & $P$ value \\
\hline In-hospital mortality & $799(3.3)$ & $327(3.1)$ & .2910 & $245(2.5)$ & 309 (3.2) & .0058 & $1.27(10.7-1.51)$ & .0072 \\
\hline Operative mortality & $962(4.0)$ & $390(3.7)$ & .1012 & $304(3.1)$ & $372(3.8)$ & .0165 & $1.21(1.02-1.42)$ & .0244 \\
\hline $\mathrm{CHA}_{2} \mathrm{DS}_{2}$-VASc $1-3$ & $242(3.0)$ & $107(2.5)$ & & $95(2.4)$ & $99(0.2)$ & & & \\
\hline $\mathrm{CHA}_{2} \mathrm{DS}_{2}$-VASc 4-6 & $633(5.7)$ & $244(5.5)$ & & $195(4.7)$ & $236(5.7)$ & & & \\
\hline $\mathrm{CHA}_{2} \mathrm{DS}_{2}$-VASc 7-9 & 87 (7.6) & $39(10.7)$ & & $15(4.9)$ & $37(10.5)$ & & & \\
\hline Composite morbidity & $4756(19.8)$ & $2043(19.38)$ & .4104 & $1690(17.3)$ & $1912(19.6)$ & $<.0001$ & $1.16(1.08-1.25)$ & $<.0001$ \\
\hline $\begin{array}{l}\text { Reoperation for bleeding/ } \\
\text { tamponade, graft, valve, } \\
\text { other cardiac reason }\end{array}$ & $936(3.9)$ & $445(4.2)$ & .1497 & $386(4.0)$ & $420(4.3)$ & .2224 & $1.09(0.95-1.25)$ & .2145 \\
\hline $\begin{array}{l}\text { Deep sternal wound } \\
\text { infection }\end{array}$ & $103(0.4)$ & $44(0.4)$ & .8891 & $44(0.5)$ & $37(0.4)$ & .4371 & $0.84(0.54-1.30)$ & .4359 \\
\hline Permanent stroke & $474(2.0)$ & $191(1.8)$ & .3226 & $161(1.7)$ & $181(1.9)$ & .2761 & $1.13(0.91-1.39)$ & .2757 \\
\hline Prolonged ventilation & $3326(13.8)$ & $1398(13.3)$ & .1610 & 1104 (11.3) & 1314 (13.5) & $<.0001$ & $1.22(1.12-1.33)$ & $<.0001$ \\
\hline New renal failure & $1371(6.0)$ & $664(6.5)$ & .0838 & $480(5.1)$ & $617(6.5)$ & $<.0001$ & $1.32(1.16-1.49)$ & $<.0001$ \\
\hline
\end{tabular}

Values are presented as n (\%) unless otherwise noted. $\mathrm{CHA}_{2} \mathrm{DS}_{2}-V A S C$, congestive heart failure, hypertension, age $\geq 75$ years, diabetes, previous stroke/transient ischemic attackvascular disease, age 65-74 years, sex category.

subanalysis of these patients, we determined the highest operative mortality was in the ablation group with $\mathrm{CHA}_{2} \mathrm{DS}_{2}$-VASc scores of 7 to 9 and the lowest mortality was also in the ablation group in patients with a $\mathrm{CHA}_{2} \mathrm{DS}_{2}$-VASc score of 1 to 3 . Additionally, perioperative morbidity including prolonged ventilation and new renal failure was also higher. However, 2-year mortality did not differ by use versus nonuse of ablation. In patients who survived past 2 years, stroke or systemic embolization and mortality were lower in the ablation group (Figure 5).

A previous single-center series demonstrated a reduction in stroke after concomitant surgical AF ablation during cardiac surgery. ${ }^{20}$ This current analysis is the first to show a long-term stroke or systemic embolization was lower after AF ablation in a CABG-only cohort. Because neither atria are opened routinely in CABG, the addition of $\mathrm{AF}$ ablation requires either omission of endocardial lesions or alteration of the CABG operation to allow for atrial access required for the Cox-maze procedure. $^{21}$ Although the exact lesion set is unknown in this dataset (data unavailable until 2014), many patients may have received an incomplete ablation set of the Cox-maze procedure, causing an underestimation of the efficacy of AF ablation.

The effect of AF ablation on operative mortality and long-term survival has not been established in CABG patients. A previous study of Medicare patients with preoperative $\mathrm{AF}$ undergoing $\mathrm{CABG}$ showed that the addition of $\mathrm{AF}$ ablation was associated with an increase in 30-day mortality that was not statistically significant (adjusted odds ratio, $1.15 ; P=.19) .^{22}$ However, another study of STS-CMS linked patients with preoperative AF demonstrated ablation was associated with lower perioperative mortality, ${ }^{23}$ but analyzed patients undergoing multiple cardiac operations, including mostly mitral valve surgery. A similar study, compiling data from 7 centers, found improved long-term survival in patients with $\mathrm{AF}$ who had concomitant ablation during CABG, valve, or CABG plus valve procedures. ${ }^{24}$

Our study found that the HR for AF ablation and mortality was not proportional over time, and that survival curves crossed at 2 years. Therefore, AF ablation was associated with a small, statistically significant higher operative mortality that was mitigated over time and became equivalent through 2 years, and per the landmark analysis, significantly lower in patients surviving past 2 years. Moreover, patients with lower $\mathrm{CHA}_{2} \mathrm{DS}_{2}$-VASc scores had lower operative mortality when undergoing $\mathrm{AF}$ ablation, which is consistent with previous reports. On the other hand, patients with high $\mathrm{CHA}_{2} \mathrm{DS}_{2}$-VASc scores had lower operative mortality if $\mathrm{AF}$ ablation was performed, suggesting an important riskbenefit consideration.

Guidelines for the treatment of $\mathrm{AF}$ recommend concomitant ablation during CABG (class 1) in whom acceptable perioperative safety is expected. ${ }^{25}$ Our study supports the recommendations that AF ablation should be performed during CABG in most patients with preoperative $\mathrm{AF}$ because after 2 years it is associated with lower stroke and mortality. Future guideline recommendations should take into account higher risk patients (eg, very elderly patients, high $\mathrm{CHA}_{2} \mathrm{DS}_{2}$-VASc). Our study also reveals that a many patients did not get treatment of AF during $\mathrm{CABG}$ surgery suggesting underuse of surgical ablation of AF. The maze procedure has become less complex with modification of lesions, application of energy sources like cryothermy 

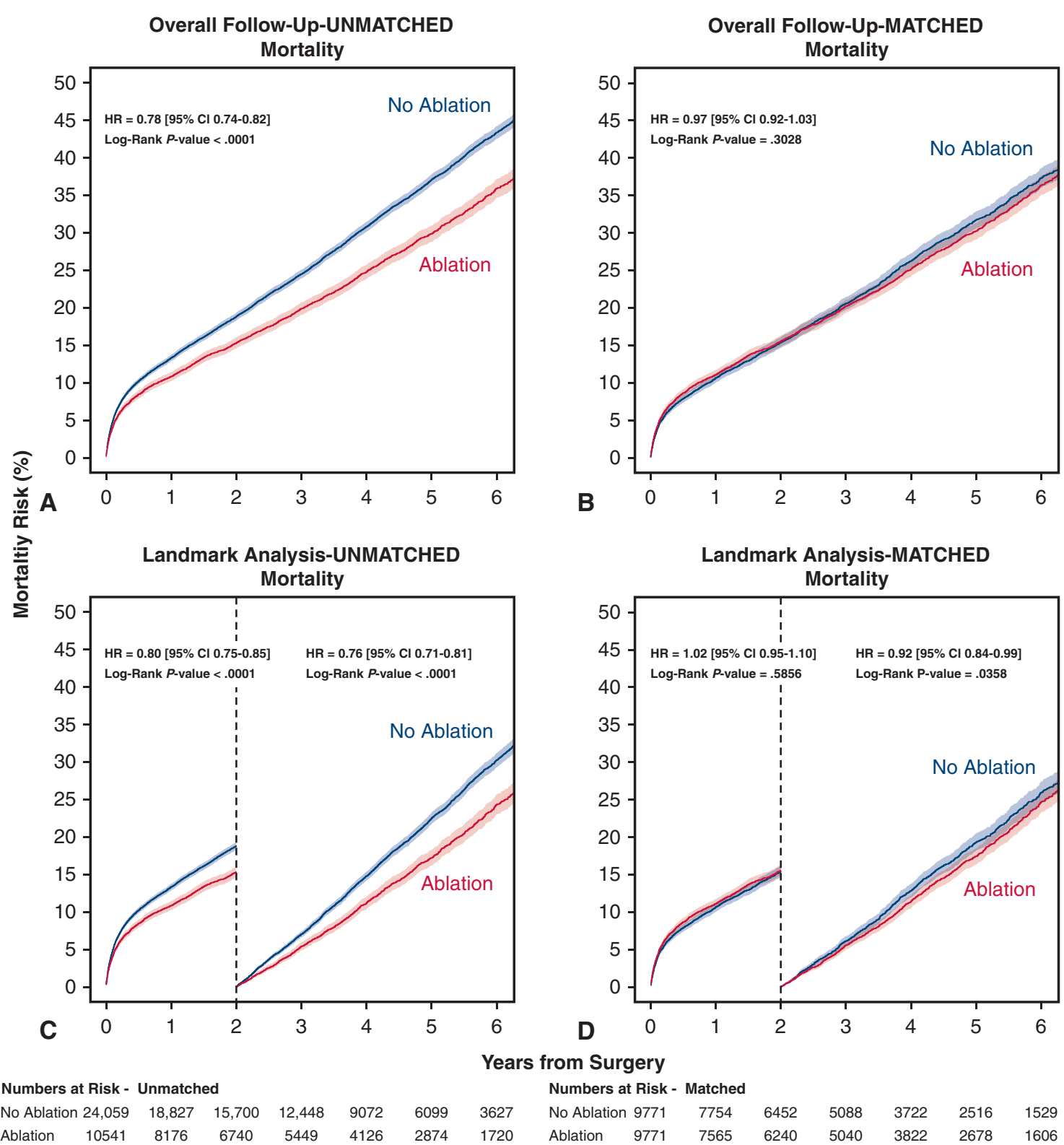

FIGURE 3. Mortality outcomes of patients in 6-year follow-up. A, Unadjusted overall data. B, Adjusted matched data. Mortality risk was similar between groups in the adjusted group $(P=.303)$. Landmark analysis results for patients surviving past 2 years. $\mathrm{C}$, Unmatched data. D, Matched data. Patients who had surgical ablation of atrial fibrillation had a lower risk of death $(P=.0358)$.

and radio frequency, and devices to close the LAA. ${ }^{26}$ Unfortunately, there were no data available on the LAA, although some variation of LAA closure is typical with AF ablation. Recent data regarding LAA closure in a population of elderly patients from the STS database showed a lower risk of readmission for thromboembolism over 3 years in patients who did have surgical occlusion of the LAA. ${ }^{27}$ The evolution of these changes are not completely reflected in this current dataset; continued advancements may further lower the perioperative risks, improve the efficacy of $\mathrm{AF}$ ablation, and reduce AF under treatment.

There has been ongoing study of whether percutaneous coronary intervention and CABG are equivalent. ${ }^{28}$ Our data raise an important treatment implication for patients with coronary artery disease and AF. The improved late survival and lower risk of stroke and thromboembolic events shown in our study should be considered when evaluating patients with coronary artery disease with concomitant $\mathrm{AF}$ and perhaps tip the treatment strategy toward surgery, 


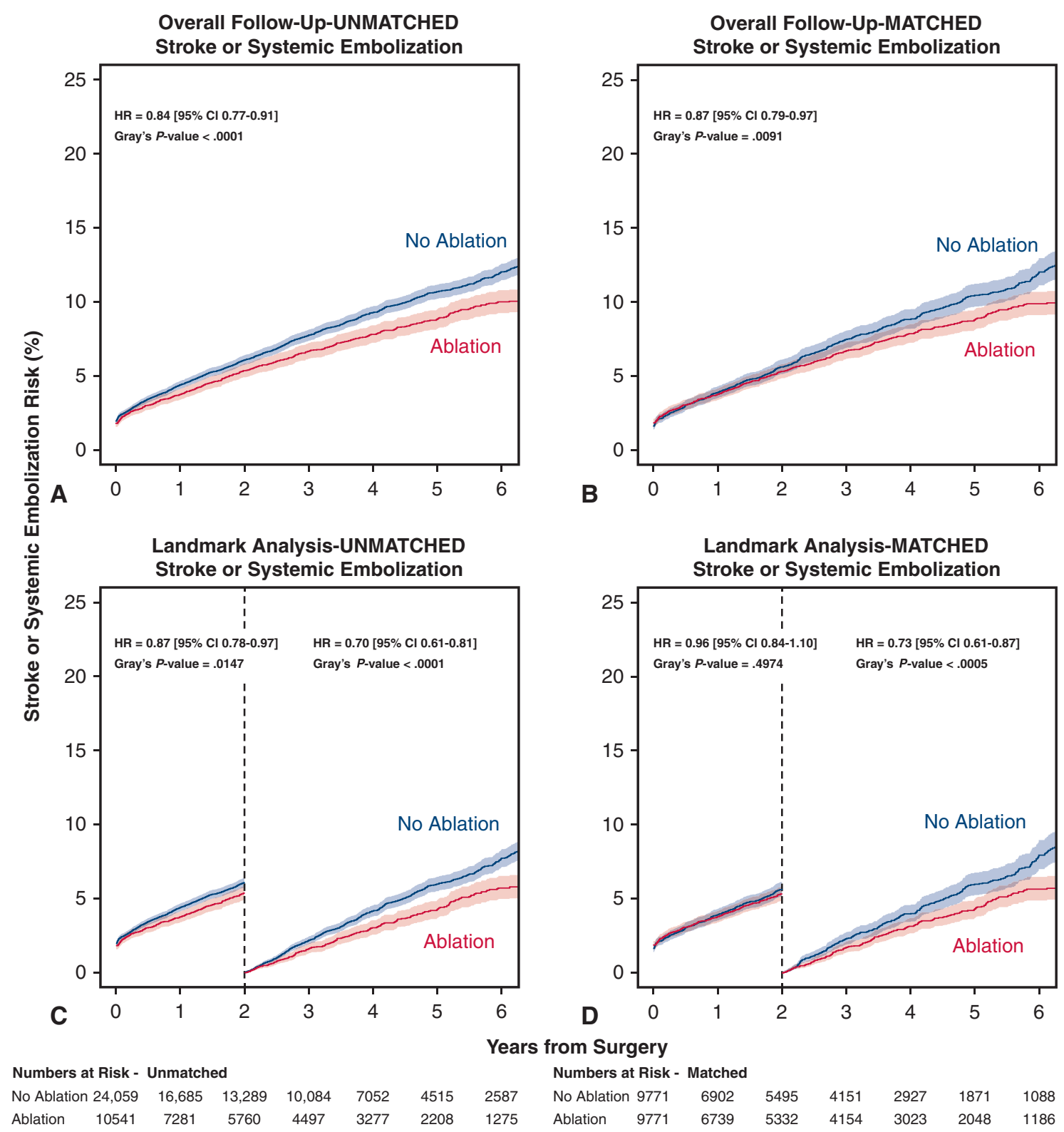

FIGURE 4. Stroke or systemic embolization outcomes of patients in 6-year follow-up. A, Unadjusted overall data. B, Adjusted matched data. Landmark analysis results for patients surviving beyond 2 years. C, Unmatched data. D, Matched data. Patients who had surgical ablation of atrial fibrillation had a lower risk of stroke or systemic embolic event $(P=.0005)$.

especially in younger patients who may benefit the most. See Video 1 for a discussion of the paper.

\section{Study Limitations}

The linkage between STS and CMS Medicare database was incomplete and may have led to unintended bias. We analyzed the unlinked subjects who could not be linked and found no significant differences in baseline characteristic with the linked subjects. This analysis is most generalizable to patients aged 65 years or older who are most susceptible to the added risks associated with extended operating times. Finally, absent from this study (due to lack of data availability) is the type and duration of preoperative AF (paroxysmal vs persistent), the AF lesions sets, and LAA management. Incomplete lesion sets of the Coxmaze procedure potentially lowered the effectiveness of $\mathrm{AF}$ ablation, and the omission of surgical LAA closure (associated with reduced risk of thromboembolism) ${ }^{27}$ both bias results to the null hypothesis.

\section{CONCLUSIONS}

$\mathrm{AF}$ ablation in $\mathrm{CABG}$ patients with preoperative $\mathrm{AF}$ is associated with lower stroke or systemic embolization at 
Preoperative AF in Patients Undergoing CABG
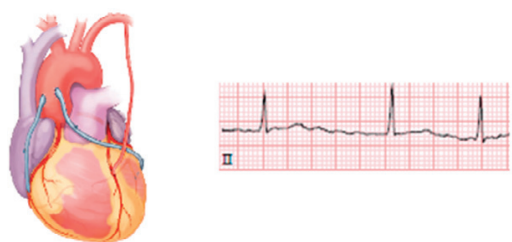
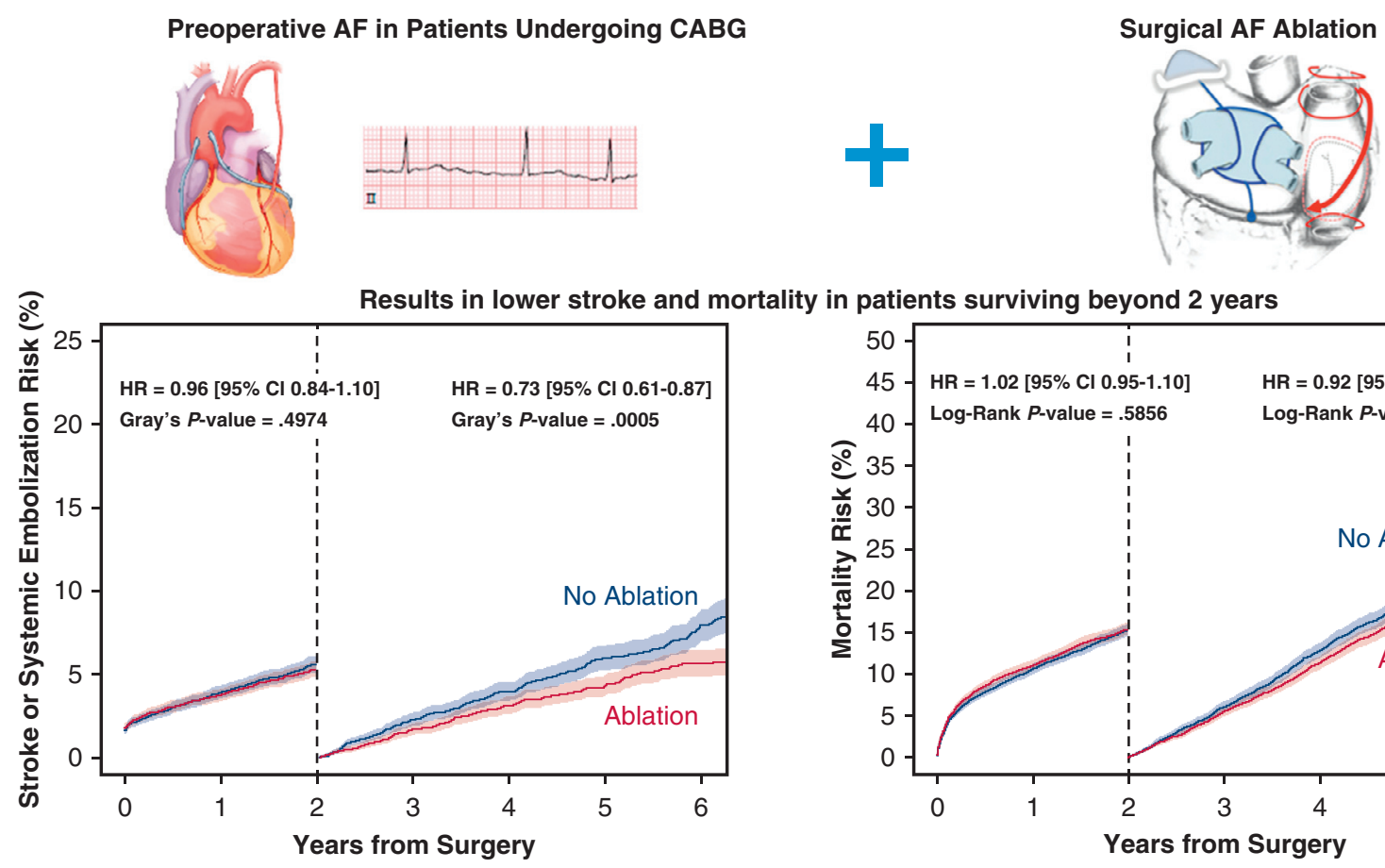

Numbers at Risk

$\begin{array}{llllllll}\text { No Ablation } & 9771 & 6902 & 5495 & 4151 & 2927 & 1871 & 1088\end{array}$

$\begin{array}{llllllll}\text { Ablation } & 9771 & 6739 & 5332 & 4154 & 3023 & 2048 & 1186\end{array}$

Results in lower stroke and mortality in patients surviving beyond 2 years

FIGURE 5. Patients undergoing isolated coronary artery bypass surgery with a history of preoperative atrial fibrillation $(A F)$ may benefit from concomitant AF ablation. The Cox-maze IV maze lesion set is shown. However, detailed lesion set information was not available in our study. Although early stroke and mortality were similar, stroke or systemic embolization and mortality for patients surviving more than 2 years was lower. $C A B G$, Coronary artery bypass graft.

5 years. The small but statistically significant higher perioperative risk should be considered in patients with vulnerabilities to increased operating time required for AF ablation. Lower mortality was observed in patients surviving past 2 years. Patients with ablation of $\mathrm{AF}$ had a lower operative mortality in the low $\mathrm{CHA}_{2} \mathrm{DS}_{2}$ VASc scores group but higher operative mortality in those with $\mathrm{CHA}_{2} \mathrm{DS}_{2}$-VASc scores of 7 to 9 , suggesting a risk-benefit consideration for high risk, elderly patients.

\section{Webcast}

You can watch a Webcast of this AATS meeting presentation by going to: https://aats.blob.core.windows.net/ media/18May01/Theater \% 201\%20Booth $\% 20134 /$ S $84 \%$ 20-\%20Update $\% 20$ of $\% 20$ surgical $\% 20$ Ablation/S84_1_ webcast_123616894.mp4.

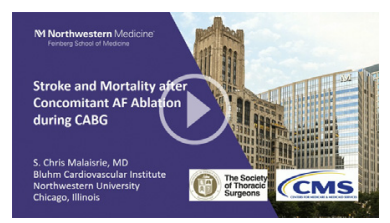

\section{Conflict of Interest Statement}

Dr McCarthy has received speaker fees from Atricure and Medtronic. Dr Friedman has received educational grants from Boston Scientific, Medtronic, and Abbott; research grants from National Cardiovascular Data Registry funded by the National Institutes of Health ( $T 32$ training grant HL069749-13), Boston Scientific, Abbott, Medtronic, and Biosense Webster; and consulting fees from Abbott; in addition, he is supported by the Joseph C. Greenfield Jr, MD, Scholar in Cardiology Award. All other authors have nothing to disclose with regard to commercial support.

The authors thank Mr and Mrs Timothy Thoelecke for their financial support of the Bluhm Cardiovascular Institute, at Northwestern University, which made this project possible.

\section{References}

1. Malaisrie SC, McCarthy PM, Kruse J, Matsouaka R, Andrei AC, GrauSepulveda MV, et al. Burden of preoperative atrial fibrillation in patients undergoing coronary artery bypass grafting. J Thorac Cardiovasc Surg. 2018;155: 2358-67.e1.

2. Saxena A, Virk SA, Bowman S, Chan L, Jeremy R, Bannon PG. Preoperative atrial fibrillation portends poor outcomes after coronary bypass graft surgery: a systematic review and meta-analysis. J Thorac Cardiovasc Surg. 2018;155: 1524-33. 


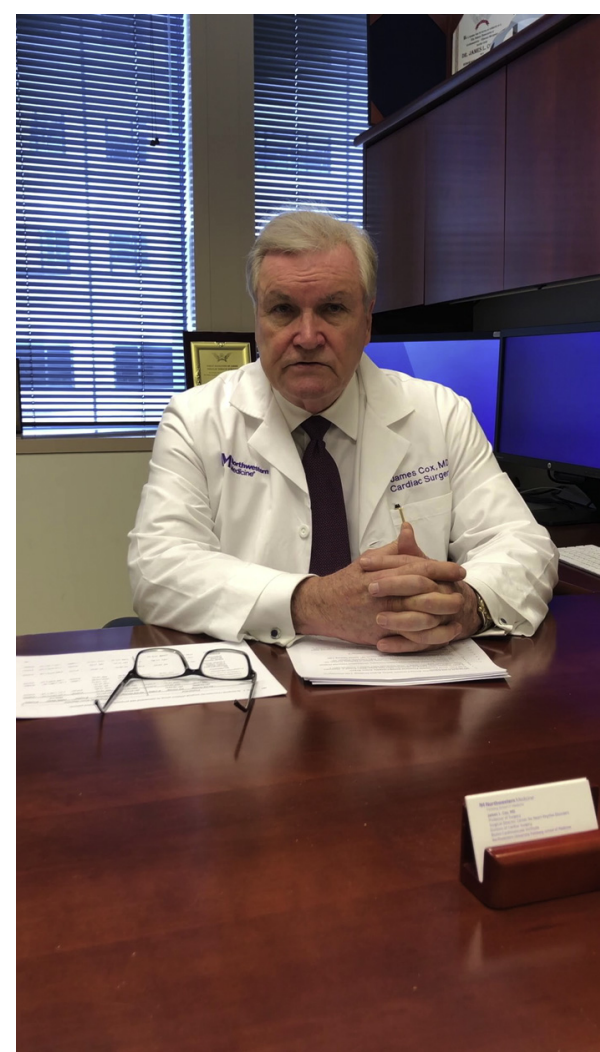

VIDEO 1. Dr James L. Cox discusses the role of atrial fibrillation ablation during coronary artery bypass graft surgery. Video available at: https:// www.jtcvs.org/article/S0022-5223(19)33073-9/fulltext.

3. Damiano RJ Jr, Gaynor SL, Bailey M, Prasad S, Cox JL, Boineau JP, et al. The long-term outcome of patients with coronary disease and atrial fibrillation undergoing the Cox maze procedure. J Thorac Cardiovasc Surg. 2003;126: 2016-21.

4. Akpinar B, Sanisoglu I, Guden M, Sagbas E, Caynak B, Bayramoglu Z. Combined off-pump coronary artery bypass grafting surgery and ablative therapy for atrial fibrillation: early and mid-term results. Ann Thorac Surg. 2006;81: 1332-7.

5. Geidel S, Lass M, Krause K, Schneider C, Boczor S, Kuck KH, et al. Persistent atrial fibrillation ablation concomitant to coronary surgery. Thorac Cardiovasc Surg. 2011;59:207-12

6. Lee R, McCarthy PM, Wang EC, Vaduganathan M, Kruse J, Malaisrie SC, et al. Midterm survival in patients treated for atrial fibrillation: a propensity-matched comparison to patients without a history of atrial fibrillation. J Thorac Cardiovasc Surg. 2012;143:1341-51.

7. Attaran S, Saleh HZ, Shaw M, Bond L, Pullan MD, Fabri BM. Comparing the outcome of on-pump versus off-pump coronary artery bypass grafting in patients with preoperative atrial fibrillation. Interact Cardiovasc Thorac Surg. 2011;13: 288-92.

8. Ad N, Holmes SD, Massimiano PS, Pritchard G, Stone LE, Henry L. The effect of the Cox-maze procedure for atrial fibrillation concomitant to mitral and tricuspid valve surgery. J Thorac Cardiovasc Surg. 2013;146:1426-34.

9. McCarthy PM, Manjunath A, Kruse J, Andrei AC, Li Z, McGee EC Jr, et al. Should paroxysmal atrial fibrillation be treated during cardiac surgery? J Thorac Cardiovasc Surg. 2013;146:810-23.
10. Musharbash FN, Schill MR, Sinn LA, Schuessler RB, Maniar HS, Moon MR et al. Performance of the Cox-maze IV procedure is associated with improved long-term survival in patients with atrial fibrillation undergoing cardiac surgery. J Thorac Cardiovasc Surg. 2018;155:159-70.

11. Jacobs JP, Edwards FH, Shahian DM, Haan CK, Puskas JD, Morales DL, et al Successful linking of the Society of Thoracic Surgeons Adult Cardiac Surgery Database to Centers for Medicare and Medicaid Services Medicare data. Ann Thorac Surg. 2010;90:1150-6.

12. Mann AF, Durham S. Death information in the research identifiable Medicare data. Vol 2017. https://www.resdac.org/articles/death-information-researchidentifiable-medicare-data. Accessed December 27, 2019.

13. D'Agostino RS, Jacobs JP, Badhwar V, Paone G, Rankin JS, Han JM, et al. The Society of Thoracic Surgeons Adult Cardiac Surgery Database: 2017 update on outcomes and quality. Ann Thorac Surg. 2017;103:18-24.

14. Shahian DM, Edwards FH, Ferraris VA, Haan CK, Rich JB, Normand SL, et al. Quality measurement in adult cardiac surgery: part 1-conceptual framework and measure selection. Ann Thorac Surg. 2007;83:S3-12.

15. O'Brien SM, Shahian DM, DeLong ER, Normand SL, Edwards FH, Ferraris VA et al. Quality measurement in adult cardiac surgery: part 2-statistical considerations in composite measure scoring and provider rating. Ann Thorac Surg. 2007; 83:S13-26.

16. Shahian DM, O'Brien SM, Sheng S, Grover FL, Mayer JE, Jacobs JP, et al. Predictors of long-term survival after coronary artery bypass grafting surgery: results from the Society of Thoracic Surgeons Adult Cardiac Surgery Database (the ASCERT study). Circulation. 2012;125:1491-500.

17. Austin PC. Using the standardized difference to compare the prevalence of a binary variable between two groups in observational research. Commun Stat Simul Comput. 2009;38:1228-34.

18. Fine JP, Gray RJ. A proportional hazards model for the subdistribution of a competing risk. J Am Stat Assoc. 1999;94:496-509.

19. Gray RJ. A class of K-sample tests for comparing the cumulative incidence of a competing risk. Ann Stat. 1988;16:1141-54.

20. Fukunaga S, Hori H, Ueda T, Takagi K, Tayama E, Aoyagi S. Effect of surgery for atrial fibrillation associated with mitral valve disease. Ann Thorac Surg. 2008;86 1212-7.

21. Cox JL, Churyla A, Malaisrie SC, Kruse J, Pham DT, Kislitsina ON, et al. When is a maze procedure a maze procedure? Can J Cardiol. 2018;34:1482-91.

22. Rankin JS, Lerner DJ, Braid-Forbes MJ, Ferguson MA, Badhwar V. One-year mortality and costs associated with surgical ablation for atrial fibrillation concomitant to coronary artery bypass grafting. Eur J Cardiothorac Surg. 2017:52:471-7.

23. Badhwar V, Rankin JS, Ad N, Grau-Sepulveda M, Damiano RJ, Gillinov AM, et al. Surgical ablation of atrial fibrillation in the United States: trends and propensity matched outcomes. Ann Thorac Surg. 2017;104:493-500.

24. Iribarne A, DiScipio AW, McCullough JN, Quinn R, Leavitt BJ, Westbrook BM, et al. Surgical atrial fibrillation ablation improves long-term survival: a multicenter analysis. The Ann Thorac Surg. 2019;107:135-42.

25. Badhwar V, Rankin JS, Damiano RJ Jr, Gillinov AM, Bakaeen FG, Edgerton JR, et al. The Society of Thoracic Surgeons 2017 clinical practice guidelines for the surgical treatment of atrial fibrillation. Ann Thorac Surg. 2017; 103:329-41

26. Cox JL, Malaisrie SC, Kislitsina ON, McCarthy PM. The electrophysiologic basis for lesions of the contemporary Maze operation. J Thorac Cardiovasc Surg. 2019;157:584-90.

27. Friedman DJ, Piccini JP, Wang T, Zheng J, Malaisrie SC, Holmes DR, et al. Association between left atrial appendage occlusion and readmission for thromboembolism among patients with atrial fibrillation undergoing concomitant cardiac surgery. JAMA. 2018;319:365-74.

28. Doenst T, Haverich A, Serruys P, Bonow RO, Kappetein P, Falk V, et al. PCI and $\mathrm{CABG}$ for treating stable coronary artery disease: JACC review topic of the week J Am Coll Cardiol. 2019;73:964-76.

Key Words: atrial fibrillation, maze, ablation, coronary artery bypass grafting 
TABLE E1. Independent Cox regression analysis for mortality and stroke or systemic embolism in the total cohort and propensity matched cohort

\begin{tabular}{lcccc}
\hline & $\begin{array}{c}\text { Unmatched unadjusted } \\
\text { hazard ratio } \mathbf{9 5} \% \\
\text { confidence interval) }\end{array}$ & $\begin{array}{c}\text { Unmatched regression } \\
\text { adjusted hazard ratio }(\mathbf{9 5} \% \\
\text { confidence interval) }\end{array}$ & $\begin{array}{c}\text { Matched unadjusted hazard } \\
\text { ratio (95\% confidence } \\
\text { interval) }\end{array}$ & $\begin{array}{c}\text { Matched regression } \\
\text { adjusted hazard ratio (95\% } \\
\text { confidence interval) }\end{array}$ \\
\hline $\begin{array}{l}\text { Mortality } \\
\text { Ablation vs no ablation }\end{array}$ & $0.78(0.74-0.82)$ & $0.95(0.9-1)$ & $0.97(0.92-1.03)$ & $0.95(0.89-1.01)$ \\
$\begin{array}{c}\text { Stroke or systemic embolism } \\
\text { Ablation vs no ablation }\end{array}$ & $0.84(0.77-0.91)$ & $0.89(0.81-0.97)$ & $0.87(0.79-0.97)$ & $0.86(0.78-0.96)$ \\
\hline
\end{tabular}

